\title{
Construction of the Cut-Off Wall for a 330mw Hydropower Project at Kishanganga in J\&K
}

\author{
Mohammad Adil Dar ${ }^{1}$, Prof (Dr) A.R. Dar ${ }^{2}$, Shazia Shafi Bhat ${ }^{3}$, Jayalakshmi \\ Raju ${ }^{4}$, Manzoor Shafi Bhat ${ }^{5}$ \\ ${ }^{1 \& 4}$ PG Scholar, Department of Civil Engineering, Kurukshetra University, Haryana, India \\ ${ }^{2}$ Professor \& Head, Department of Civil Engineering, NIT, Srinagar, India \\ ${ }^{3 \& 5}$ PG Scholar, Department of Civil Engineering, NIT, Srinagar, India
}

\begin{abstract}
Cutoff Wall indicated is a thin watertight wall of clay or concrete (concrete in this case) built up from a cutoff trench to reduce seepage through any natural water passages-joints and cleavage planes in the rock massif or passages between ground constituents such as boulders and cobbles and through existing granular material such as sands and gravels and deepen the flow lines to make them pass beyond the dam area. It is also known as core wall. The use of diaphragm walls as cut-off or seepage barriers or as structural elements has been on the civil engineering and geotechnical scene in a relatively widespread manner since just after the Second World War.
\end{abstract}

Key Words: watertight, diaphragm walls, seepage barriers, structural elements, world war.

\section{Introduction}

Kishanganga Hydropower Project[1] is located in the state of J\&K in district Bandipora. The Installed Capacity of project is 330MW.It is being constructed on Kishanganga River, consisting of $37 \mathrm{~m}$ high concrete face rockfill dam in Gurez valley, underground Power House which is located in Bandipora. A $23.5 \mathrm{Kms}$ long HRT(Head Race Tunnel) in which $14.75 \mathrm{Kms}$ is to be constructed by Tunnel Boring Machine (TBM) and 8.75 Kms by Drill Blast Method (DBM). FIGURE-1 shows the various stages in cut-off wall construction.

The construction of the Kishanganga Hydropower Project (KGHP) dam also involves foundation treatment work to ensure both stability and impermeability (water tightness) of the underlying foundation rock to avoid unacceptable under-dam water seepage. A key element in the design is the installation of a cut-off wall[2] (or diaphragm wall) under the dam whose purpose is to stem under-dam seepage. Salient nominal features of the KHEP cut-off wall are given in TABLE-1

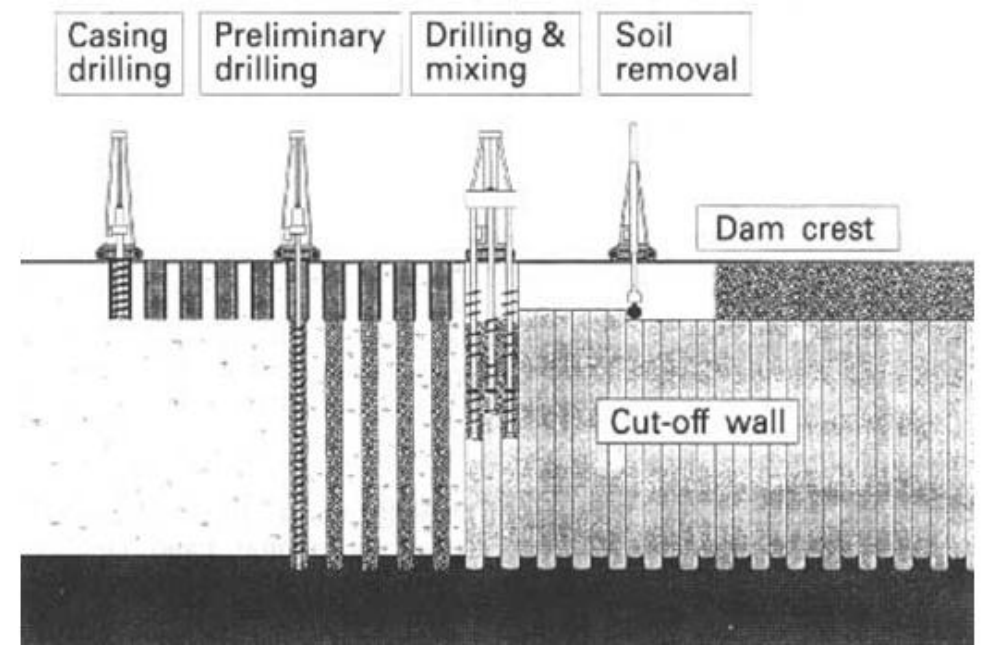

\begin{tabular}{|l|l|}
\hline Thickness & $1 \mathrm{~m}$ \\
\hline Max. depth & $35 \mathrm{~m}$ \\
\hline Mean depth & $30 \mathrm{~m}$ \\
\hline Extent & $120 \mathrm{~m}$ \\
\hline Surface Area & $3600 \mathrm{sg} \cdot \mathrm{m}$ \\
\hline \multicolumn{2}{|c|}{ TABLE-1 } \\
\hline
\end{tabular}

Figure-1

Overburden

II. Geological Description

The depth of the overburden along the dam axis varies from $12 \mathrm{~m}$ to $33.55 \mathrm{~m}$ with hole collars being at around Elevation-1, $365.00 \mathrm{~m}$ (FIGURE-2).

Permeability of the overburden ranges from $2.1 \times 10^{-3} \mathrm{~cm} / \mathrm{sec}$ to $98 \times 10^{-3} \mathrm{~cm} / \mathrm{sec}$. 


\section{Bedrock}

In general the bedrock is greenish, hard, compact, strong, but jointed. The dam area on both river banks around the proposed dam axis is exposed to Panjal volcanic that comprises of quartz, feldspar, muscovite and chlorite minerals.

\section{River Bed Geology}

At the dam site, width of river is about $90 \mathrm{~m}$. The main Channel is $30 \mathrm{~m}$ wide \& is confined to the right bank that is defined by expanses of slope wash material and low-level fluviatile terrace deposit on the left bank comprising river-borne material. The river borne material generally consists of boulders ranging in size from $15 \mathrm{~cm}$ to $30 \mathrm{~cm}$ in size and pebbles of volcanics, granite and gneiss embedded in a sandy silt matrix. The larger sized boulders are also anticipated in the river deposits. According to interpretation and projection of boreholes, the depth of the overburden in the river bed section ranges between $18 \mathrm{~m}$ to $29 \mathrm{~m}$. There lies bedrock of massive to moderately jointed, compact, hard volcanics below the river overburden.

\section{Construction Method (Review and Choice)}

In consideration to the difficult geology existing in the project area, with rock hardness ranging from $95 \mathrm{MPa}$ to $265 \mathrm{MPa} \&$ the bouldery nature of the subsoil overlying the bedrock, several methods of cut-off wall construction were examined \& finally Reverse circulation drilling with large diameter borings was implemented.

\section{General}

\section{Engineering Considerations Pertaining To Construction}

The Plastic Concrete Cutoff Wall (COW) of $1 \mathrm{~m}$ thickness \& 35m depth was constructed by excavating the trench of $1.0 \mathrm{~m}$ width by grab and chisel. The trench area was first shattered by light controlled blasting to shatter the boulders etc in order to facilitate the excavation by grabbing. The excavation was carried out by mechanical grab. Walls of excavated trench were kept supported by bentonite slurry. Chisel was used to break the boulders if any boulder is still unbroken and obstructs the grabbing. Excavation and concreting was done as a sequence of primary and secondary panels. Pre-splitting \& blasting of cutoff wall trench area plan $\&$ elevation is given in FIGURE-2



Figure-2 Pre-Splitting \& Blasting Of Cutoff Wall Trench Area

\section{Trench \& Guide Wall}

Guide Walls need to be constructed prior to the diaphragm wall for the following reasons

- Guidance to ensure the correct alignment of the excavation. Panel numbers and their locations shall be accurately and clearly set out on the guide walls.

- Stability of the upper trench that could be affected by the vertical surcharge induced by the excavating crane and other heavy jobsite traffic adjacent to the trench.

- Protection against instability of the uppermost soil layers caused by washing Caused by fluctuating levels of bentonite slurry during excavation.

- Prevention to the collapse of the top of the trench due to equipment loads close to the trench . 
- Support for the vertical loads imposed by the extraction of the stop ends and whose extractor jacks are supported by the guide wall. The guide walls are normally constructed as a cast-in-situ reinforced concrete unit.

\section{Drilling \& blasting}

\section{Phases Of Construction}

The methods used were closely assessed from technical point of view and their respective difficulties were also considered, along with their favorable aspects. Drilling \& blast sequence of cut off wall is given in FIGURE-3
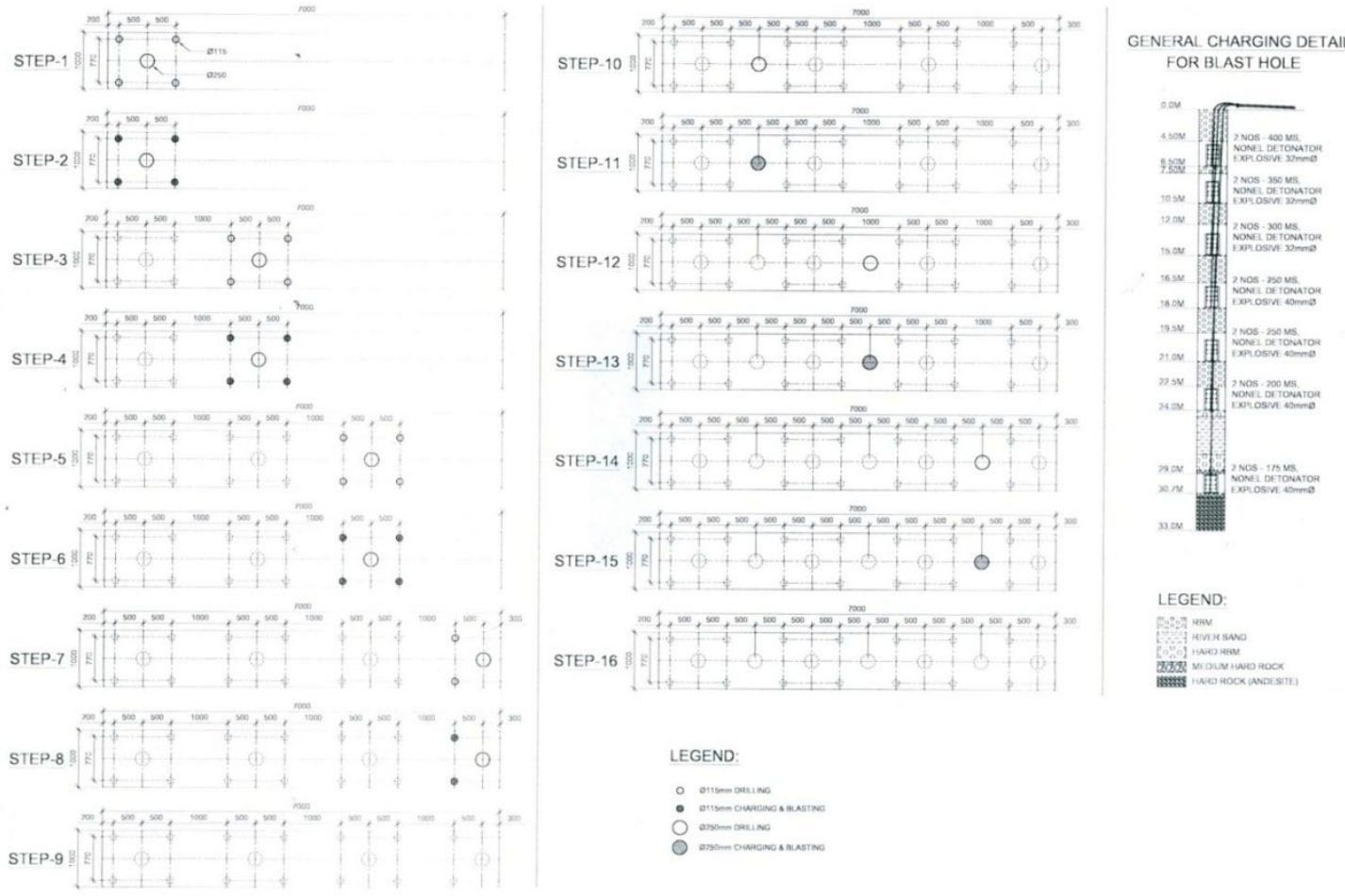

Figure-3 Drilling \& Blast Sequence Of Cut Off Wall

\section{Drilling Sizes}

Drilling shall be performed using two gauges: dia. $115 \mathrm{~mm}$ and dia. $250 \mathrm{~mm}$.

Typically the blast holes shall be dia. $115 \mathrm{~mm}$ and the relief holes shall be dia. $250 \mathrm{~mm}$. However, some central blast holes along the cut-off axis shall also be of dia. $250 \mathrm{~mm}$.

The dia. $115 \mathrm{~mm}$ drill string shall have DIA $76 \mathrm{~mm}$ drill rods by $3 \mathrm{~m}$ length and the casing is dia. $114 \mathrm{~mm} \mathrm{x}$ $3 \mathrm{~m}$. The dia. $250 \mathrm{~mm}$ drill string shall have dia. $114 \mathrm{~mm}$ drill rods by $3 \mathrm{~m}$ length and the casing is dia. $245 \mathrm{~mm} \mathrm{x}$ $3 \mathrm{~m}$.Stabilizers on the drilling rods shall keep the rod /casing assembly co-axial, thereby favoring straight drilling and mitigate vibrations. Drill collars (heavy gauge drill pipes) shall be inserted in the drill string, just above the DTH hammer for hole straightness and verticality and to act as a vibration dampener, all in favor of verticality.

\section{Drilling Procedure}

Hole Drilling

In accordance with the daily programme, the machine will be set up at required locations. Verticality of the mast must be checked and corrected if necessary prior to the commencement of any hole. Having started the drill rig and the compressor and checked the air pressure, drilling shall commence. Drilling is progressed by adding internal rod and casing elements, typically every $3 \mathrm{~m}$ of drill advancement. When final depth is reached drilling shall stop and the ring bit disconnected by a slight reverse rotation to allow retrieval of the inner drill string. In designated holes an inclinometer test for verticality is carried out. The blasting dia. $75 \mathrm{~mm}$ PVC casing is lowered down the hole (dia. $115 \mathrm{~mm}$ ) to case it. The steel drill casing is then retrieved and set ready for drilling the next hole. In the 4-hole blasting arrangement, the steel drill casing could be left within the hole, only if absolutely required, to protect the holes from subsequent drilling damage. Then casing shall then be withdrawn from all four holes, one at a time, in one operation. 


\section{Drilling Pattern and Sequence for Primary Panels}

The drilling pattern that has been prepared based on past experience, both in diaphragm wall trenching through rock and boulder strata and general drilling and blasting practice.

The drilling pattern represents a 7-metre stretch consisting of:

- 14 No. $x$ dia. $115 \mathrm{~mm}$ holes.

- 06 No. $x$ dia. $250 \mathrm{~mm}$ holes.

Therefore, for the drilling and blasting preparatory operation to the cut-off wall excavation, for a $120 \mathrm{~m}$ long wall, the number of such base stretches shall be:

$120 \mathrm{~m} / 7 \mathrm{~m}=17$ units.

With such an arrangement, the total number of holes is nominally:

- 240 No. $x$ dia. $115 \mathrm{~mm}$ holes.

- 120 No. $x$ dia. $250 \mathrm{~mm}$ holes.

That is, a total of 360 holes.

The sequence of drilling and then firing of the blast holes of the defined pattern is, with Reference to the schematic, as follows:

- Drilling of corner holes 1-2-3-4 (DIA 115mm blast holes) to depth of T.O.R. (Top of Rock)

$+500 \mathrm{~mm}$

- $\quad$ Drilling of central DIA 250mm relief hole.

- Charge and fire the 4 corner blast holes.

The annular void created by the DIA $250 \mathrm{~mm}$ hole between the DIA115 mm holes surrounding it will act as a free-face for the blast energy. In the meantime - except for when actual blasting takes place - the drill rig is moved to a stretch typically 20 meters away so that there is no interference with the drilling and the previously drilled holes being monitored and charged with explosive. Once two successive 4-hole modules have been completed (drilled and blasted), then the drill rig can return to the 1-metre gap left between these and drill a central DIA $250 \mathrm{~mm}$ hole that is a blast hole and, therefore, shall be charged and fired according to the lithology encountered.

\section{Charging and Firing the Hole}

- For charging the hole it is intended to use long delay Nonel (175, 200, 250, 300, 350,400 and $450 \mathrm{~ms}$ intervals) at multiple intervals.

- Initiation system will be from bottom to top; which is known as BOS or Bottom Initiation System.

- It is estimated - based on the drill-log observed along the COW axis - that the charge density in the blast holes shall be in the range of 0.7 to $1.5 \mathrm{~kg} / \mathrm{m}$ depending upon the toughness of rock available at intermediate levels.

- DIA115 mm holes with a DIA $250 \mathrm{~mm}$ hole at the centre of this module shall be blasted all at once. This module of $4+1$ holes repeats itself every after $1000 \mathrm{~mm}$ interval. This repetitive module will be blasted one after another with the suitable charges.

- Positioning and amount of charge in each hole will be dictated by the ground conditions; so also will the variation in the charge position within the holes of the same4-hole module.

- In the rock socket the first charge will be placed in position with a nominal $300 \mathrm{~mm}$ cushion below the charge to avoid any damage to the underlying bed rock. (There will be a further $350-500 \mathrm{~mm}$ cushion due to presence of sub-grade drilling).

- Depending on the depth of the cut-off, there may be 6 or more charges placed within the hole at those locations, dictated by adverse soil conditions (e.g. large boulders)

- The blast holes will be cased with PVC pipes jointed with a socket joint. (75mm O.D. \& 70.4mm I.D.)

- $\quad$ Each charge will be pre-packed on the ground in a PVC charge-tube (63mm O.D. with 57mm I.D.) which will be lowered down hole to the designated depth defined during drilling.

\section{Drilling and Firing Secondary Holes}

- After completing the blasting in one primary panel for the first sets of the (4+1) holes sequences, it is planned to come back to the space in between the two pre-blasted patterns and drill the DIA $250 \mathrm{~mm}$ hole.

- During drilling, the cuttings exhausted by the drill will be observed and collected along with the noted change in the rate of drilling and in the variation in the drilling noise due to change in the strata underground. These data will be meticulously recorded for each and every hole.

- Accordingly the degree of fracture or fragmentation in the strata beneath caused due to impact of the blasted holes from the two adjacent blasted patterns will be determined. 
- This will guide the requirement of blasting and its amount per metre of depth, as well as the levels. Once the blasting requirement is determined, the same method of charging with pre-packed charges made ready on ground will be lowered down hole and the blast initiated.

- $\quad$ Based along the same lines, the next intermediate DIA250mm holes will be drilled and blasted (if required).

- One of the major concerns of secondary drilling is the danger of intercepting an undetonated explosive column, with a high risk of detonation while operating a drill so close in unstable rock. This secondary blasting shall contribute to the shattering the rock mass in the region of the misfired hole thereby favoring subsequent excavation.

\section{Bedrock - Investigation and Protection}

In the blasting activity for the rock socket, the first charge will be placed in position with a nominal 300 $\mathrm{mm}$ cushion below it to avoid any damage to the underlying bed rock. The drilling for this has been carefully analyzed and will be driven to sub-grade so that a further $350-500 \mathrm{~mm}$ cushion for rock protection will be produced. During drilling of the blast holes, one hole in the first $(4+1)$ module shall be extended $2 \mathrm{~m}$ to $3 \mathrm{~m}$ beyond the required depth, in order to permit conducting a water pressure test to ascertain the soundness and permeability of the bedrock (before blasting operation).

This shall be done every third panel, corresponding to approximately every $20 \mathrm{~m}$ along the alignment.

The DIA $115 \mathrm{~mm}$ hole will yield the naturally occurring condition of the rock. The recorded values will act as a base reference for the seepage parameters.

Secondary drilling after the blasting in the primary (4+1 hole) modules shall be performed with holes of DIA $250 \mathrm{~mm}$. The first such hole in each panel shall also be progressed 2 to $3 \mathrm{~m}$ beyond the required blasting depth. These holes shall also allow a water pressure test to be conducted in the pocket at the base, thereby investigating the permeability of the rock following the blasting.

The observations for the second stage water pressure testing will also be recorded and compared to those of the primary water pressure testing. This comparison will help in understanding the impact of blasting on the surrounding bed rock. It will be verification as to the adequacy of the blast cushion as one of the key measures taken not to disturb the bedrock. If the Lugeon values remain unaltered, the confirmation of the goodness of the operating procedures is demonstrated.

\section{Bentonite Slurry}

The bentonite/water ratio (B/W) usually adopted, ranges between $2 \%$ and $8 \%$, according to the bentonite and water quality and the soil type. The weight of the fresh mud, as function of the W/B ratio, will be within 1.01 and $1.08 \mathrm{~g} / \mathrm{cm} 3$, the Marsh viscosity generally within 35 and 45 seconds.

Slurry will be maintained at all times $50 \mathrm{~cm}$ below the top of the guide walls (preferably $15 \mathrm{~cm}-30 \mathrm{~cm}$ max. with the grab submerged in the trench) and, in any case, not less than $1.50 \mathrm{~m}$ above the existing water table.

\section{+Slurry mud preparation and storage}

- Bentonite slurry mud is prepared by mixing the bentonite powder to the water at the mixing plant.

- High turbulence mixers shall be used to ensure complete wetting of the bentonite particles and avoid lumps. A mud hopper mixer could also be installed.

- In the mud hopper, the required amount of bentonite powder flows at constant rate (out of the special funnel), falling on a pre-determined flow rate of water. Both, water and bentonite are consequently in right proportion and are mixed by a Venturi tube; the mix is circulated a few times through a centrifugal pump in the mud hopper tank.

- The mix is then pumped into the slurry ponds for hydration, where a constant circulation of the mud is provided. Care is to be taken to avoid the use of bentonite slurry before the appropriate hydration (at least 12 hours according to IS: $9556-1980$ preferably $\geq 18$ hours will be adopted). Full bentonite hydration is actually achieved after 24 hours.

\section{Maintaining stability of excavation}

The stability of the trench is maintained (or improved) by the drilling fluid(the slurry). Level is to be maintained within about $0.5 \mathrm{~m}$ from the top of the guide walls. During chiseling operations, this level shall be that with the chisel already within the trench, just as it is for grabbing, where it is that with the grab within the panel trench under excavation.

\section{Pumping the slurry to the trench}

The slurry has to be pumped into the trench at the same rate as the soil and slurry are removed by the excavating equipment. During normal trenching operations, the slurry circulates in a circuit between the desanding unit and the panel being excavated. This means that, if sampling of the bentonite slurry indicates it is becoming heavy through an increased sand content, a submersible pump shall be lowered down the trench to 
pump some of it back to the settlement ponds and run it through the de-sander, where it will be regenerated by adding fresh mud if necessary to restore the rheological characteristics. When the consumption of drilling fluid increases requiring more slurry, then fresh slurry or recycled slurry is pumped from the storage ponds to the panel trench. In case of apparent anomalous fluid loss during excavation and or chiseling, slurry pumping into the trench will be increased while excavation is temporarily suspended, in order to maintain constant the slurry level inside the trench.

\section{Excavation of primary panel trenches}

- The minimum length of one panel is $2.50 \mathrm{~m}$, as determined by the length of the grab. Whenever the soil conditions and/or the geometry of the wall permit, longer, multiple 'bite' primary panels, consisting of 3 consecutive 'bites' can be constructed. (e.g. triple bite with a left bite $2.5 \mathrm{~m}$ - right bite $2.5 \mathrm{~m}$ - centre bite 0.5 to $2.0 \mathrm{~m}=$ total primary panel length 5.5 to $7.0 \mathrm{~m}$ ). Excavation \& concrete detail of primary panel is shown in FIGURE-4.

- Prior to commencing the excavation of the primary panel, the mud reservoir is to be created by excavating within the guide walls, for a depth of $800 \mathrm{~mm}$ to $1.0 \mathrm{~m}$, a trench extending for approximately $3.0 \mathrm{~m}$ beyond the ends of the panel trench. This will be filled with bentonite slurry and will act as a surge tank to minimize the fluctuations of the bentonite level within the trench as the grab is lowered into it and removed from it during grabbing operations.

- The mud reservoir thus created must have protection grids placed over it so as to avoid any risk of personnel falling into it.

- The excavating rig (crane with suspended grab) will set up on location and start the first bite in compliance with the location tolerance of $\pm 15 \mathrm{~mm}$ along the cut-off axis. The panel number and end markings shall be read off the top of the guide walls.

- Excavation of the primary panel shall entail 3 bites and, typically, will produce a $7.0 \mathrm{~m}$ long primary trench.

- This trench shall, however, be progressed either in single bites to final depth or in a constant down-staging of the three bites so that the trench is effectively at the same level across the 3-bite extent. Depth intervals for the lead of each lateral bite can be of the order of $3 \mathrm{~m}$ to $5 \mathrm{~m}$, depending on the soil conditions. In bedrock for the socketing, it can be less.

- Chiseling is carried out by either the same excavation crane or by the service crane. The procedure requires the lifting of the chisel by about 2-3 metres from the point of impact and dropping it using the crane's free fall feature on the hoisting winches.

- For verticality correction and/or panel inner and outer face rectification; a scraper chisel is provided and shall be used as required.

- All chisels shall have a safety line connected to them so that in the event of any cable failure, it can always be retrieved by the crane using the safety line.

- When the primary panel trench excavation and clean-up is completed, tubular stop ends (special heavy cylindrical DIA $1000 \mathrm{~mm}$ steel form work) shall be set in place at the ends. This involves placing the stopend hydraulic extractors on top of the guide first and carefully lowering the stop-ends through these.

- Once the stop-ends have been retrieved, the primary panel is completed and shall have the dimensions and shape indicated.

- Based on the ground conditions, primary panel trenches may be reduced to $6 \mathrm{~m}$ with a resultant $4 \mathrm{~m}$ concrete panel. 


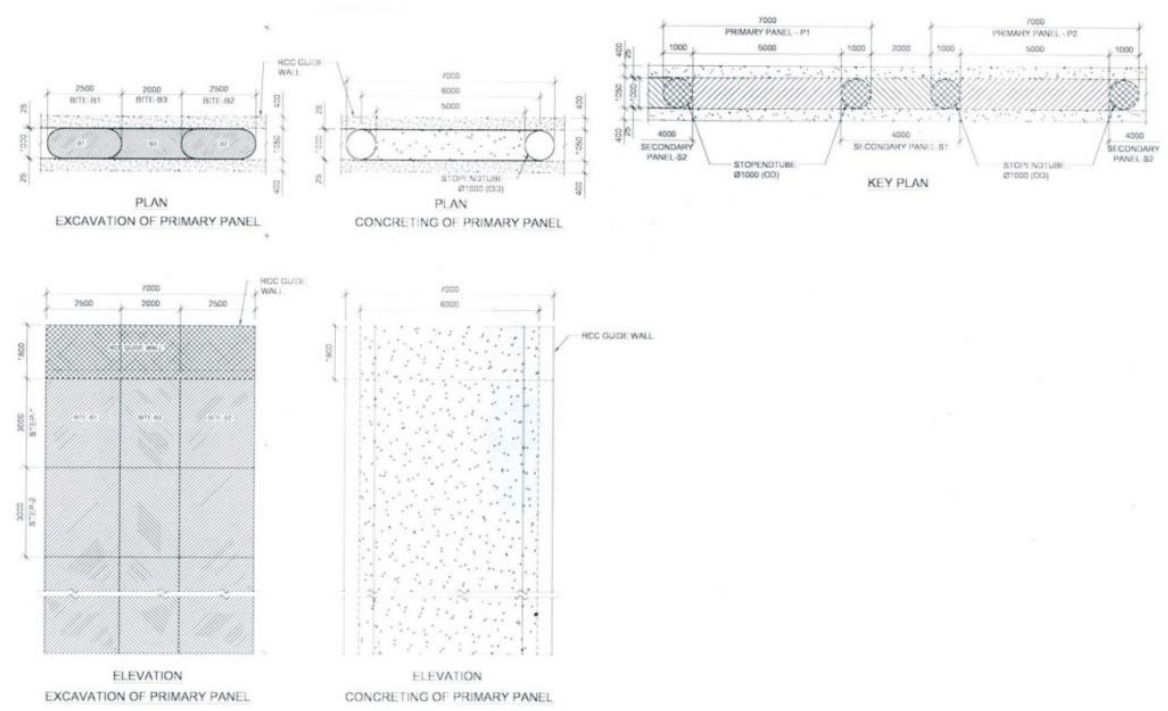

Figure-4 Excavation \& Concrete Detail Of Primary Panel

\section{Excavation of secondary panel trenches and the formation of joints}

- The secondary panels shall have a nominal 2.0-metre of fresh excavation with the $1.0 \mathrm{~m}$ diameter shafts at each end. It will, therefore, be a $4.0 \mathrm{~m}$ long panel.

- To ensure continuity of the diaphragm wall, joints between successive panels are formed when excavating the secondary panel trenches by having the secondary panel trench enter the DIA $1.0 \mathrm{~m}$ full-depth shaft left by the stop-ends in the casting of the primary panel.

- This is equivalent to having a fixed nominal $500 \mathrm{~mm}$ overcut into the concreted primaries and a theoretical arc joint of $1.57 \mathrm{~m} .[4]$

- Secondary panels are usually "single bite" panels with an effective length of $4.0 \mathrm{~m}$.

- Should ground conditions so dictate a shift in the primary panels with their trench length reduced to $6.0 \mathrm{~m}$, then either a $3.5-\mathrm{m}$ or a $4.0-\mathrm{m}$ concreted secondary panel would be possible.

- The construction of secondary panels should not start before 24 hours of completion of the adjacent primary panels.

\section{Construction of Cut Off Wall Panels}

- Diaphragm wall construction begins with the trench being excavated in discontinuous sections or panels using heavy grabs or trenching mills.

- At Kishanganga, the excavation tool shall be a heavy wire rope-suspended mechanical clamshell grab. This will be operated by using a large lattice boom hydraulic crawler crane (e.g., an 80-tonne Kobelco 7080). The grabs have a $2500 \mathrm{~mm} \times 1000 \mathrm{~mm}$ nominal bite dimension, are approx. 4.5 metres tall with the jaws opened and weigh either 7 tonnes or 9 tonnes.

- The grab is equipped with a sensor that relays any deviation along the cut-off wall axis, the transverse axis to the cut-off alignment and the rotation about its vertical axis. At each grabbing bite the data relevant to the grab's position at the bottom of the panel excavation is transmitted to a datalogger in the crane operator's cabin. The operator can see the exact actual position of the grab with respect to the vertical and correct theoretically designated position in real time.

- Adjustable top guides are fitted to the grab to direct its angle of attack to correct any tendency to deviate from the cut-off alignment; i.e., in the transverse direction, whenever such deviation is noted and recorded.

- Also, the use of heavy excavation chisels shall be adopted to correct any deviation of the panel trench as required.

- Typically primary single or multiple bite panels are constructed first, followed by the construction of intermediate secondary or closing panels.

- Panel excavation is carried out in a predefined sequence to enable the construction of a continuous cut-off wall with clearly identifiable joint locations.

- This is achieved by constructing alternate "primary" panels first, followed by the excavation of the intermediate "secondary" or "closure" panels. 
Chiseling

The chisel Sizes used are

- 10 -ton box chisels $(1000 \mathrm{~mm} \times 1500 \mathrm{~mm})$.

- 10 -ton cross chisel (DIA 900mm).

- 6-ton star chisel (DIA 900mm).

- 6-ton scraper chisel - 1500mm x 1000mm.

The chisels have a dual purpose: firstly, break up any boulders that were insufficiently fractured by the surgical blasting carried out; break up boulders or rock pieces that are too large to be removed from the trench; secondly, they are to be used to rectify any tendency of deviation from vertical.

\section{Stop-ends}

Stop-ends are the formwork installed at the ends of a primary panel to create a free end to the primary panel where the adjacent secondary panel trench shall connect, thereby creating a point of continuity in the paneltype cut-off wall.

\section{Stop-end Removal}

- Once concreting of a primary panel has taken place, the time shall be recorded on the concrete placement report. After 60 minutes, the stop-ends shall be jacked upwards approx. $400 \mathrm{~mm}$ to "break" the concrete-steel bond. Stop-end jacking shall be recorded on the Stop-end Retrieval Report.

- Reference markings will be made on the stop-ends to ensure their vertical position is known at any time. These can be made with a simple waterproof permanent marker and read off with respect to either the extractor base frame or the guide wall.

- At intervals of 30 minutes following the initial lift, a $300 \mathrm{~mm}$ stop-end jacking operation shall commence until the stop-ends have been raised $1600 \mathrm{~mm}$ (i.e., $400 \mathrm{~mm}+300 \mathrm{~mm}+300 \mathrm{~mm}+300 \mathrm{~mm}+300 \mathrm{~mm}$ ) within approximately $60^{\prime}+30^{\prime}+30^{\prime}+30^{\prime}+30^{\prime}=180$ mins. or 3 hours after completion of the primary panel concreting[3].

- Although the stop-ends are independent and each has its own extractor jacking device, the two stop-ends shall be jacked up simultaneously: what is done to one must be immediately done to the other so that they are always in the same nominal status.

- Following a 2-hour wait, a further $400 \mathrm{~mm}$ jacking lift is to be performed, bringing the total lift to 2.0 metres after 5 hours.

- Any signs of the stop-ends "sticking" shall be reason for effecting another 30-minute 300mm series of lift. Should the resistance to lift be evident, such cycles may continue.

- The stop-ends can be completely removed 16 hours after completion of concreting of the primary panel, based on the mix design adopted for the plastic concrete. Concrete Placement

- Concrete shall be placed within the panel trench by means of tremie pipes supported by a crane and, when necessary, subjected to jerk to promote the outflow of the concrete from the submerged bottom of the tremie. With the steel tremie suspension device in place, the tremie pipe (minimum DIA $250 \mathrm{~mm}$ ) is introduced into the trench down to $200 \mathrm{~mm}$ from the bottom. FIGURE-5 shows work in progress.

\section{DESIGN}

The Mix Design of the Cut off wall is given in TABLE-2

\begin{tabular}{|l|l|l|}
\hline Class of Concrete & & \\
\hline Aggregate size & 20 & 20 \\
\hline Maximum slump (mm) & 200 & 200 \\
\hline OPC $(\mathrm{Kg})$ & 205 & \\
\hline PPC $(\mathrm{Kg})$ & & 220 \\
\hline Bentonite & 82 & 82 \\
\hline Total Cement $(\mathrm{kg})$ & 205 & 220 \\
\hline w/C & 1.95 & 2 \\
\hline Normal water & 399.75 & 440 \\
\hline Total water & 400 & 440 \\
\hline Total Aggregate & 1270 & 1150 \\
\hline Coarse aggregate $20 \mathrm{~mm}$ & 300 & 300 \\
\hline Coarse aggregate $10 \mathrm{~mm}$ & 300 & 300 \\
\hline Fine aggregate & 670 & 550 \\
\hline Retarder & $0.6 \%, 1.2 \mathrm{~kg}$ & $0.5 \%, 1.1 \mathrm{~kg}$ \\
\hline
\end{tabular}

Table-2 


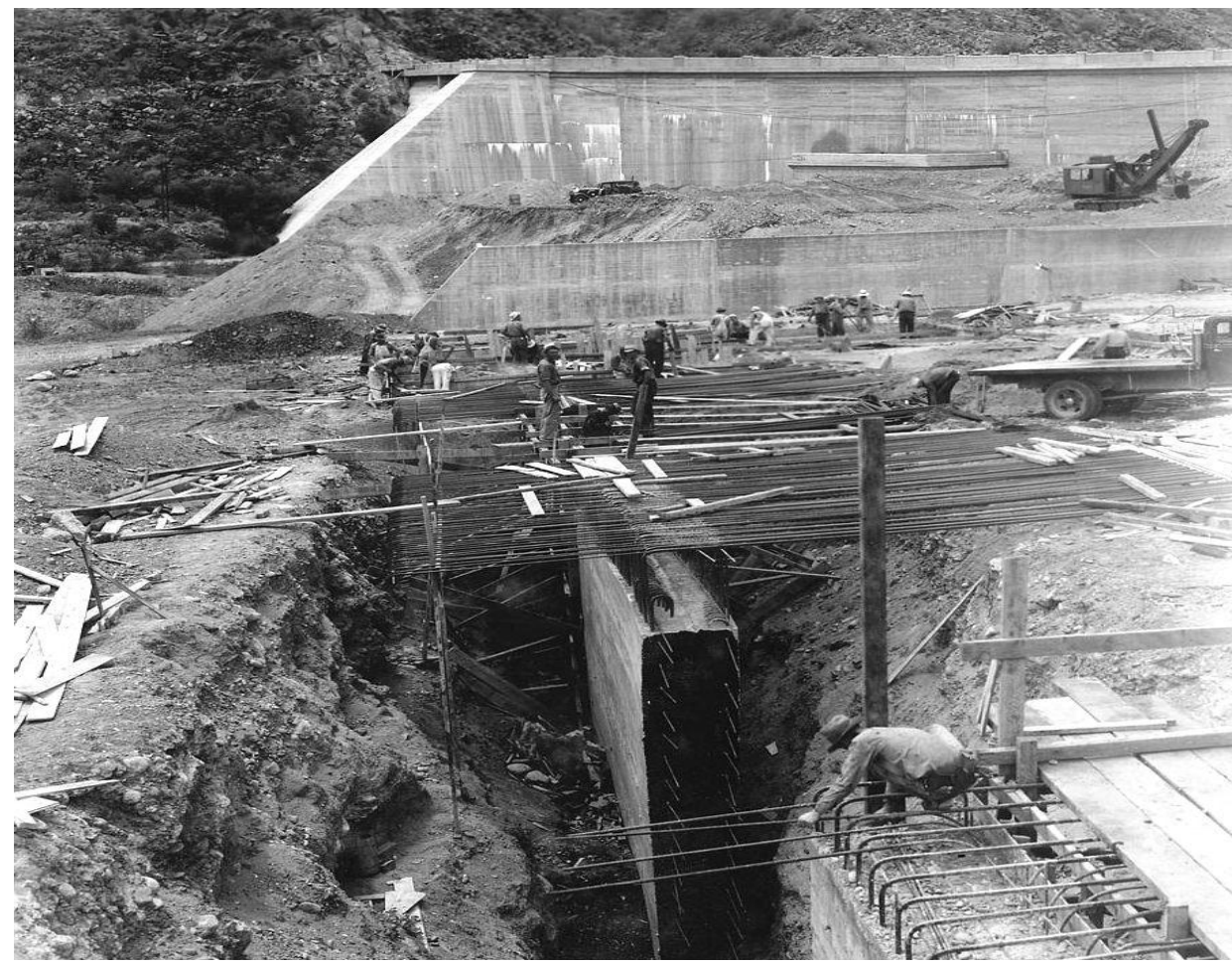

Figure-5 Picture Taken During Construction

\section{Conclusion}

Cut-off Wall for Kishanganga Hydropower Project located in the state of $J \& K$ in district Bandipora was successfully constructed to reduce seepage through any natural water passages into the dam. It also involved foundation treatment work to ensure both stability and impermeability of the underlying foundation rock to avoid unacceptable under-dam water seepage. All guidelines were properly followed to ensure its smooth construction.

\section{Refrences}

[1]. Handman, F.W.A., 1929. "The Arapuni (New Zealand) hydro-electric power development". Minutes of Proceedings Institution of Civil Engineers Vol 228 (Part 2), pp230-257, Paper No 4739.

[2]. Simpson, D.E., Phipps, M., Ressi, A.L., 2006. "Constructing a cutoff wall in front of Walter F George Dam in 100 feet of water", Hydro Review, Volume 25, No 1, March 2006, HCI Publications.

[3]. IS $-9556,1980$

[4]. Bruce, D.A. (2000 and 2001). "An introduction to the deep mixing method as used in geotechnical applications." Prepared by Geosystems, L.P., Document No. FHWA-RD-99-138, March, 143 p

[5]. Bruce, D.A. and S. Stefani. (1996). "Rehabilitation of Beaver Dam: A Major Seepage Cut-off Wall," Ground Engineering, Vol. 29, No. 5, June, pp. 40-45.

[6]. Brunner, W. (2005). "CSM Cutoff System". Promotional Material from Bauer Maschinen.

[7]. Cyganiewicz, J.M. (1988). "Construction of a Cutoff Wall at Fontenelle Dam," Proceedings of 16th ICOLD Conference, San Francisco, CA, June, Volume 5, pp. 227-230.

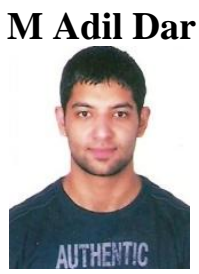

\section{Author Details}

The Author has received his B.E(Hons) in Civil Engineering from M.S.R.I.T Bangalore. He is Presently pursuing his M-Tech in Structural Engineering from Kurukshetra University. The Author has published papers in numerous High Quality Peer Reviewed International Journals and International Conferences. His research interests include Earthquake Engineering, Bridge Engineering \& Steel Structures. He is a Chartered Engineer from Institution of Engineers, India \& Chartered Structural Engineer from the Institution of Structural Engineers. He is the Fellow of IAEME, IIBE \& ICC(CIDC) \& Life Member of ISE(I), ISET, ICI, IBC, ISSE, ISCA, ISTE, ISTAM, ISRMTT, IndACM, IE(I), IAENG, , IET(U.K) \& Member of IAStructE, IABMAS(Italy), IStructE, ASCE,IE(Ireland) \& IEAust. 


\section{Prof(Dr) A.R.Dar}

The Author has received his B.E in Civil Engineering from R.E.C Srinagar (Presently N.I.T Srinagar), M.E (Hons) in Structural Engineering from I.I.T Roorkee \& Ph.d in Earthquake Engineering from University of Bristol U.K under prestigious Commonwealth Scholarship Award. He is presently working as a Distinguished Professor \& Head of Civil Engineering Department in N.I.T Srinagar. The Author has published papers in several International journals \& Conferences. His research areas include Earthquake Resistant Design, Tall Structures, Structural Dynamics, RCC design, Steel Design \& Prestressed Design . He is the Life Member of several professional bodies in structural engineering. He was the Advisor in UPSC Board 2011 for conducting interviews of IES candidates .He was also empanelled as Paper setter \& Examiner for Public Service Commission ,Himachal Pradesh in Civil Engineering. He is presently the Senior most Professor \& holds many administrative responsibilities in the same institution.

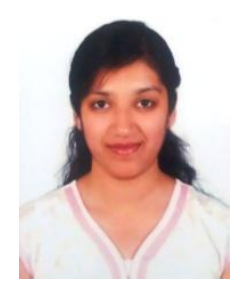

\section{Jayalakshmi Raju}

The Author has received his B.E(Hons) in Civil Engineering from M.S.R.I.T Bangalore. She is Presently pursuing her M-Tech in Structural Engineering from Kurukshetra University.. She has published many papers in numerous peer reviewed International Journals and International Conferences. She has presented technical papers in many State \& National Level Technical Events. She has also participated in many technical events like cube casting \& technical debates. Her research interests include Steel Design, RCC Design \& Bridge Engineering. She is the Fellow of IAEME \& member of ASCE, ACI, IEAust, SEFI, \& ISCE. 